\title{
A Needs Assessment Study of Hospital Pharmacy Residency Preceptors
}

\author{
Christine Truong, Andrew Wyllie, Toni Bailie, and Zubin Austin
}

\begin{abstract}
Background: Canadian pharmacy residency programs rely on preceptors to support the growing demand of graduates wishing to pursue hospital residencies. Understanding the educational needs of these preceptors is important to ensure that they are well prepared to deliver successful programs.
\end{abstract}

Objective: To determine what new and experienced residency preceptors self-identify as learning needs in order to become more effective preceptors for pharmacy residents.

Methods: A needs assessment of preceptors from the 31 accredited Canadian general hospital pharmacy residency programs was conducted. The study had 4 key components: interviews and focus group discussions with key informants, a pilot study, an online survey, and member checking (seeking clarification and further explanation from study participants). The residency coordinators and a convenience sample of 5 preceptors from each program were invited to participate in the survey component.

Results: Of a possible 186 participants, 132 (71\%) responded to the survey. Of these, 128 (97\%) were confident that they met the 2010 standards of the Canadian Hospital Pharmacy Residency Board (CHPRB). Preceptors ranked communication skills, giving effective feedback, and clinical knowledge as the most important elements of being an effective preceptor. Managing workload, performing evaluations, and dealing with difficult residents were commonly reported challenges. Preceptors expressed a preference for interactive workshops and mentorship programs with experienced colleagues when first becoming preceptors, followed by 1-day training sessions or online learning modules every other year for ongoing educational support. The most beneficial support topics selected were providing constructive feedback, practical assessment strategies, small-group teaching strategies, effective communication skills, and setting goals and objectives.

Conclusions: This study identified several learning needs of hospital residency preceptors and showed that preceptors would appreciate educational support. Utilization of these results by residency program administrators, the CHPRB, and faculties of pharmacy could be beneficial for residency programs across Canada.

Key words: hospital pharmacy residency, preceptor, preceptor development, pharmacy education

Can J Hosp Pharm 2012;65(3):202-208

\section{RÉSUMÉ}

Contexte : Les programmes canadiens de résidence en pharmacie comptent sur les précepteurs pour soutenir la demande grandissante des diplômés en pharmacie désirant poursuivre une résidence hospitalière. Il est donc important de comprendre les besoins en éducation de ces précepteurs afin de s'assurer qu'ils sont bien préparés pour réussir la mise en œuvre de leurs programmes.

Objectif : Déterminer les besoins d'apprentissage que les précepteurs, novices et chevronnés, ont eux-mêmes définis pour remplir leur rôle de façon plus efficace auprès des résidents en pharmacie.

Méthodes : Une évaluation des besoins des précepteurs a été effectuée à partir des 31 programmes généraux de résidence en pharmacie d'hôpital agréés au Canada. L'étude comportait quatre éléments clés : des entrevues et des entretiens de groupe avec des informateurs clés, une étude pilote, un sondage en ligne et une vérification auprès des participants (clarifications et explications plus en détail demandées aux participants à l'étude). Les coordonnateurs et cinq précepteurs de chaque programme de résidence, constituant un échantillon de convenance, ont été invités à participer au volet sondage.

Résultats : Des 186 participants éventuels, 132 (71\%) ont répondu au sondage. Parmi ceux-ci, 128 (97\%) étaient certains de répondre aux normes de $2010 \mathrm{du}$ Conseil canadien de la résidence en pharmacie d'hôpital (CCRPH). Les précepteurs ont classé les techniques de communication, la rétroaction efficace et les connaissances cliniques comme étant les éléments les plus importants d'un précepteur compétent. Gérer la charge de travail, effectuer les évaluations et composer avec des résidents difficiles étaient des défis couramment signalés. Les précepteurs préféraient participer à des ateliers interactifs et à des programmes de mentorat avec des collègues expérimentés lorsqu'ils débutaient comme précepteurs, puis à des séances de formation d'un jour ou à des modules d'apprentissage en ligne bisannuels pour ce qui est du soutien éducatif continu. Les sujets choisis relatifs au soutien présentant le plus d'avantages étaient la rétroaction constructive, les stratégies d'évaluation pratiques, les stratégies d'enseignement par petits groupes, les techniques de communication efficace et l'établissement des buts et objectifs.

Conclusions : Cette étude a cerné plusieurs besoins d'apprentissage des précepteurs des résidents en pharmacie d'hôpital et a montré que les précepteurs tireraient profit d'un soutien éducatif. L'utilisation de ces résultats par les administrateurs des programmes de résidence, le CCRPH et les facultés de pharmacie pourrait être avantageuse pour l'ensemble des programmes de résidence au Canada.

Mots clés : résidence en pharmacie d'hôpital, précepteur, perfectionnement des précepteurs, enseignement de la pharmacie

[Traduction par l'éditeur] 


\section{INTRODUCTION}

$\mathrm{P}$ harmacy graduates in Canada have the option to pursue general hospital residencies. The pharmacy residency, a 1year program that takes place in a hospital setting, consists of rotations under a preceptorship model. The model relies on volunteer preceptors who have a broad range of clinical knowledge and practical experience. ${ }^{1}$ The preceptors, who are experienced and competent clinicians, build supportive one-to-one teaching and learning relationships with pharmacy residents, who are usually newly qualified clinicians. ${ }^{2}$ Preceptors have been shown to play an important role in the success of residency programs and the education of pharmacy students, ${ }^{1}$ even though most have received little formal training to prepare them. ${ }^{3}$ Understanding preceptors' specific educational needs is important for institutions to best prepare their staff for preceptorship. Doing so will ultimately further the goal of the Canadian Society of Hospital Pharmacists (CSHP) to have more residency-trained pharmacists, ${ }^{4}$ especially since the demand for hospital residency positions in Canada has been increasing. ${ }^{5}$

A literature search of the MEDLINE, PubMed, and International Pharmaceutical Abstracts databases, in July 2010, yielded publications demonstrating that preceptorship is an effective method of teaching in medicine, nursing, and veterinary medicine, in addition to pharmacy, ${ }^{2,6-11}$ and supporting the implementation of training programs for preceptors in these fields. ${ }^{2,6-11}$ Kaviani and Stillwell ${ }^{7}$ specifically highlighted the importance of formal preparation of preceptors and ongoing preceptor development. Formal preparation has been shown to enhance teaching and learning opportunities for both students and preceptors. ${ }^{7,12}$

Another key finding from the literature review was the accreditation standards for pharmacy residency programs released in January 2010 by the Canadian Hospital Pharmacy Residency Board (CHPRB). ${ }^{13}$ These standards, which were based on CSHP standards of practice, included guidelines for program administrators to develop competency-based residency programs. The standards were set not only for residents, but also for preceptors. They highlighted specific knowledge, skills, and practice experience that preceptors should possess to be successful role models and to assist in the development of residents' skills. ${ }^{13}$

Many Canadian universities offer preceptor training programs for individuals wishing to become preceptors in any field. ${ }^{14,15}$ However, these programs are intended for novice preceptors and focus on the development of various general skills to become effective preceptors. We are not aware of any programs that target experienced preceptors. The challenge for residency programs is to recognize that current preceptors also need training and mentoring ${ }^{16}$ to meet evolving standards. $\mathrm{CSHP}^{13}$ and the American Society of Hospital Pharmacists ${ }^{17}$ recently identified this need for continuing educational material to support preceptor development.
Another gap in existing knowledge is the lack of information about pharmacy-specific preceptor development programs in Canada and the United States. A supplemental literature search focused on pharmacy and medical education revealed no published papers providing guidance for preceptor development. In these 2 countries, certain studies have assessed pharmacy preceptors' and residents' opinions of, feelings about, and experiences related to preceptorship, ${ }^{5,18-20}$ but to our knowledge, no studies have investigated the types of educational support, specifically for development of pharmacy preceptors, that would be beneficial. Training programs for new preceptors present general preceptorship skills, some of which may be transferable, but they do not focus on hospital pharmacy practice. Marriott and others ${ }^{21}$ described an Australian preceptor preparation course for community pharmacists, which consisted of several online learning modules. Although the topics seem relevant, it is not known whether the course would be suitable for Canadian pharmacists, given differences in pharmacy education and practice between Australia and Canada.

In an effort to fill some of the gaps in the existing literature, we set out to determine what new and experienced residency preceptors self-identify as learning needs in order to become more effective preceptors for pharmacy residents. The specific objectives were to obtain a better understanding of how preceptors perceive their training and preparation for preceptorship, to design a relevant study to assess preceptors' learning needs, and to determine what educational support can be offered to preceptors.

\section{METHODS}

This study was a needs assessment of preceptors from the 31 accredited general hospital pharmacy residency programs across Canada. Nonaccredited programs were excluded because there was no assurance that they adhered to the CHPRB accreditation standards, which served as the basis for our survey study. The study had 4 key components: interviews and focus group discussions with key informants, a pilot study, an online survey, and member checking.

The interviews and focus group discussions with key informants were conducted to seek opinions and help design the survey. Individual interviews were conducted over the telephone. The key informants included members of the CHPRB, pharmacy faculty involved in developing continuing education for pharmacists, and hospital pharmacists who were experienced or novice preceptors or who intended to become preceptors. The conversations with key informants included discussion of specific areas of focus for survey questions and how to ensure optimal validity. Focus group discussions were conducted in small groups to further develop the ideas generated during the interviews. At the beginning of each discussion, participants were presented with a brief synopsis of the research project, the purpose of the discussion group, and 
their responsibilities. Participants were asked to review a draft of the survey, to evaluate existing questions drafted by the investigators, and to design new questions. After each focus group, the survey was revised to incorporate participants suggestions and comments. Purposive sampling was used to recruit participants for the interviews and focus group discussions, to ensure that discussions were productive and informative. The participants were selected from 4 hospitals in the Toronto area (Mount Sinai Hospital, The Hospital for Sick Children, the University Health Network, and St Michael's Hospital).

The pilot study was conducted with 2 small groups ( 4 and 3 preceptors, respectively) to ensure that the methods and procedures planned for the survey were acceptable and feasible. Participants in the pilot survey provided feedback that was used to validate the survey. The time required to complete the survey was recorded for pilot participants, to ensure that respondents in the main study would be able to complete the survey in 10 to $15 \mathrm{~min}$. Convenience sampling was used to recruit participants for the pilot survey. Those who took part in the pilot study were not eligible to participate in the actual survey, to avoid rehearsal bias.

The main survey was conducted using a Canadian-based online survey website, Fluidsurveys.com. A few months before the survey was released, notification was sent to all residency program directors and coordinators. One week before the survey was made available online, an e-mail invitation, including a link to the online survey, was sent to the coordinator of each of Canada's 31 accredited programs. The coordinators were also asked to distribute the link to 5 residency preceptors in their programs, for a total of 186 potential respondents. Participants were given 1 month to complete the survey. Reminder emails were sent 1 week after the survey was made available and 1 week before the survey period ended. Convenience sampling was used to recruit survey participants, as described above.

Member checking, the final step in the study, is the process of seeking clarification and further explanation from study participants to ensure that participants' viewpoints have been faithfully interpreted. ${ }^{22}$ Member checking was also performed to ensure internal validity, evaluate interpretive variability, and provide opportunity for feedback. The memberchecking session was conducted 2 weeks after the survey was closed. Purposive sampling of a small group of preceptors who had completed the survey was used to recruit participants for the member-checking session.

Qualitative data collected from the interview and focus group sessions were used in designing the survey. The survey comprised demographic questions, 10 Likert scale questions, 3 ranking questions, 2 multiple-choice questions, and 10 open-ended questions. Statistical analyses of the results were descriptive. The free-text responses were analyzed qualitatively. Surveys were classified as incomplete if the participant had not answered one or more questions. All questions that were completed, whether or not the whole survey had been completed, were included in the analysis.

\section{RESULTS}

\section{Interviews and Focus Groups}

During the interviews, key informants suggested that, as a first step, we review CHPRB standards, current educational resources, existing challenges, and the role that faculties of pharmacy could play. These suggestions were used in conducting the focus groups, drafting the survey questions, and revising the survey with each subsequent focus group. The final version of the survey (available by request to the corresponding author) focused on residency preceptors' thoughts and opinions about the following topics:

- CHPRB standards

- skills and qualities of effective preceptors

- challenges faced by preceptors

- educational support programs for preceptors

- incentives or benefits of serving as a preceptor for pharmacy residents

\section{Pilot Survey}

The average length of time it took participants to complete the pilot survey was $14 \mathrm{~min}$ (range 7-22 $\mathrm{min}$ ), within the target time of $15 \mathrm{~min}$. Participants in the final pilot study session made no additional suggestions.

\section{Main Survey}

Of the 186 potential respondents from across Canada, 132 (71\%) responded to the online survey. Of those, $106(80 \%)$ answered every question in the survey. Responses came from preceptors with different educational backgrounds, workplace settings, and preceptorship experience (Table 1). When asked about the CHPRB standards, 88 (67\%) of the preceptors were familiar with the standards before completing the survey. When presented with the full standards, 128 (97\%) of the 132 respondents agreed or strongly agreed that they were confident they met the standards.

When asked about their confidence and competence when first starting to serve as preceptors for pharmacy residents, 33\% of respondents (40/121) gave a neutral rating (midway between very confident/competent and not very confident/competent). The majority of preceptors felt they had learned how to be good preceptors after experiential learning with other preceptors, regardless of whether those role models were considered good or poor preceptors. Similarly, several respondents noted that having completed a residency themselves was extremely helpful as preparation for serving as a preceptor. 


\section{Table 1. Characteristics of 132 Respondents* to an Online Survey Assessing Needs of Pharmacy Residency Preceptors}

\begin{tabular}{|c|c|c|}
\hline \multirow{2}{*}{$\begin{array}{l}\text { Characteristic } \\
\text { Education }\end{array}$} & \multicolumn{2}{|c|}{ No. (\%) of Respondents* } \\
\hline & & \\
\hline $\begin{array}{l}\text { Undergraduate pharmacy degree } \\
\text { (e.g., BScPhm, BSP) }\end{array}$ & 109 & (83) \\
\hline Entry-level PharmD & 1 & (1) \\
\hline Postgraduate PharmD & 33 & $(25)$ \\
\hline Pharmacy residency & 88 & $(67)$ \\
\hline Other & 25 & (19) \\
\hline \multicolumn{3}{|l|}{ Experience in hospital practice (years) } \\
\hline Mean & \multicolumn{2}{|c|}{14.9} \\
\hline Range & & \\
\hline \multicolumn{3}{|l|}{ Workplace settingt } \\
\hline Community hospital & 22 & $(17)$ \\
\hline Teaching hospital & 112 & (85) \\
\hline Ambulatory clinic & 10 & (8) \\
\hline Other & 10 & (8) \\
\hline \multicolumn{3}{|l|}{ Type of employment } \\
\hline Full time & 116 & (88) \\
\hline Part time & 15 & (11) \\
\hline Casual & 1 & $(1)$ \\
\hline \multicolumn{3}{|l|}{ Experience as a preceptor } \\
\hline \multicolumn{3}{|l|}{ No. of years } \\
\hline Mean & \multicolumn{2}{|c|}{9.7} \\
\hline Range & \multicolumn{2}{|c|}{$0-30$} \\
\hline \multicolumn{3}{|l|}{ No. of experiences } \\
\hline Mean & \multicolumn{2}{|c|}{18.8} \\
\hline Range & \multicolumn{2}{|c|}{$0-250$} \\
\hline Preceptor training & \multicolumn{2}{|c|}{$n=125$} \\
\hline Courses dedicated to preceptorship & 43 & (34) \\
\hline Workshops dedicated to preceptorship & 95 & (76) \\
\hline $\begin{array}{l}\text { Online learning modules related } \\
\text { to preceptorship }\end{array}$ & 22 & (18) \\
\hline Forums or networks for preceptors & 24 & (19) \\
\hline Use of preceptor training manual & 68 & (54) \\
\hline
\end{tabular}

Preceptors rated almost all of the skills and qualities offered in the survey as important or very important for effective preceptors (Table 2). The top 3 skills and qualities ranked as "very important" were communication skills, giving effective feedback, and clinical knowledge in the area of practice. Skill in conducting research was deemed the least desirable, with only $3 \%$ of respondents rating it as "very important". When ratings of "very important" and "important" were grouped, the top 3 results were the same.

To determine challenges and barriers, respondents were asked to rate listed items on a 5-point scale ranging from "often a barrier" to "never a barrier". Respondents could also enter free-text responses if they had experienced other challenges and barriers. Only 2 of the respondents (2\%) perceived clinical knowledge or experience as a regular challenge. Preceptors reported that managing workload, evaluating residents, and dealing with difficult residents (including those who were not prepared and those who did not meet expectations or standards) were common challenges.

Respondents expressed interest in various forms of resources and educational support to help them become more effective as preceptors (Figure 1). They believed that, besides having completed a residency themselves, attending interactive workshops and participating in mentorship programs with more experienced preceptors would have best increased their ability and readiness to serve as preceptors for pharmacy residents when they first took on this responsibility. More experienced residency preceptors stated that 1-day training sessions or online electronic learning modules every other year would have been beneficial for ongoing educational support. Topics for educational support that most preceptors thought would be helpful (selected by more than $90 \%$ of respondents) are shown in Table 3.

Questions about incentives and benefits were divided into 3 categories: professional, personal, and skills. Participants rated the listed incentives and benefits and could enter free-text responses for other items. In the professional category, noteworthy incentives and benefits of serving as a preceptor for pharmacy residents were sharing knowledge, keeping current with changes in the profession, and helping new graduates integrate into the profession. Personal benefits, such as learning from residents, watching residents learn and grow, and reflecting on one's own practice, were all rated very highly.

For the analysis of qualitative data generated by open-ended questions, the investigators collectively developed a list of recurring themes. Each investigator individually coded the data according to these preset themes. Multiple themes were often identified in a single response. The most prominent themes are described here.

Teaching skills: Several responses related to interest in teaching and the skills to teach effectively (36 comments). One preceptor noted that "precepting a student is not the same as providing patient care. The skills and knowledge required to be a good preceptor are generally not taught to us as part of a curriculum and most learn via chance." Another preceptor was aware that "flexibility and ability to assess a resident's learning style and adjust your own teaching style quickly and appropriately are important because a rotation can go badly quickly if there is a mismatch between teaching and learning."

Time management and departmental support: Another recurring theme was the importance of time management skills and departmental support (26 comments). As noted above, managing workload was a commonly reported challenge.

Individual program variability: Variability among residency programs was apparent in the free-text responses, which referred to respondents' own specific residency programs or coordinators/directors (27 comments). For example, one preceptor appreciated "residency coordinators [orienting] new 
This single copy is for your personal, non-commercial use only.

For permission to reprint multiple copies or to order presentation-ready copies for distribution, contact CJHP at cjhpedit@cshp.ca

Table 2. Skills and Qualities Important for Pharmacy Residency Preceptors, as Rated by 118 Respondents

Importance; No. (\%) of Respondents*

\begin{tabular}{|c|c|c|c|c|c|c|}
\hline Skill or Quality & $\begin{array}{c}\text { Very } \\
\text { Important }\end{array}$ & Important & Neutral & $\begin{array}{l}\text { Somewhat } \\
\text { Important }\end{array}$ & $\begin{array}{c}\text { Not } \\
\text { Important }\end{array}$ & Rank† \\
\hline Communication skills & 72 & 26 & 2 & 0 & 0 & 1 \\
\hline Giving effective feedback & 62 & 36 & 2 & 0 & 1 & 2 \\
\hline $\begin{array}{l}\text { Clinical knowledge in area of } \\
\text { practice }\end{array}$ & 60 & 36 & 3 & 1 & 0 & 3 \\
\hline Interprofessional skills & 47 & 49 & 3 & 0 & 1 & 4 \\
\hline Evaluating skills & 46 & 48 & 6 & 0 & 0 & 5 \\
\hline Organizational skills & 43 & 50 & 5 & 2 & 0 & 6 \\
\hline Decision-making skills & 42 & 53 & 6 & 0 & 0 & 7 \\
\hline $\begin{array}{l}\text { Scientific reasoning and } \\
\text { problem-solving skills }\end{array}$ & 42 & 50 & 8 & 0 & 0 & 7 \\
\hline Time management skills & 41 & 56 & 3 & 0 & 0 & 9 \\
\hline $\begin{array}{l}\text { Individual or small group teaching } \\
\text { skills }\end{array}$ & 40 & 54 & 4 & 2 & 0 & 10 \\
\hline Skills to motivate learners & 30 & 56 & 13 & 2 & 0 & 11 \\
\hline Expectation-setting skills & 27 & 60 & 13 & 0 & 0 & 12 \\
\hline Leadership skills & 26 & 64 & 9 & 1 & 0 & 13 \\
\hline $\begin{array}{l}\text { Setting goals for the resident in the } \\
\text { rotation }\end{array}$ & 24 & 62 & 13 & 2 & 0 & 14 \\
\hline Critical appraisal skills & 21 & 64 & 12 & 3 & 0 & 15 \\
\hline Skills in conducting research & 3 & 23 & 51 & 19 & 5 & 16 \\
\hline
\end{tabular}

* Percentages across rows may not sum to 100 because of rounding.

tRanking is based on percentage identifying the skill or quality as very important.

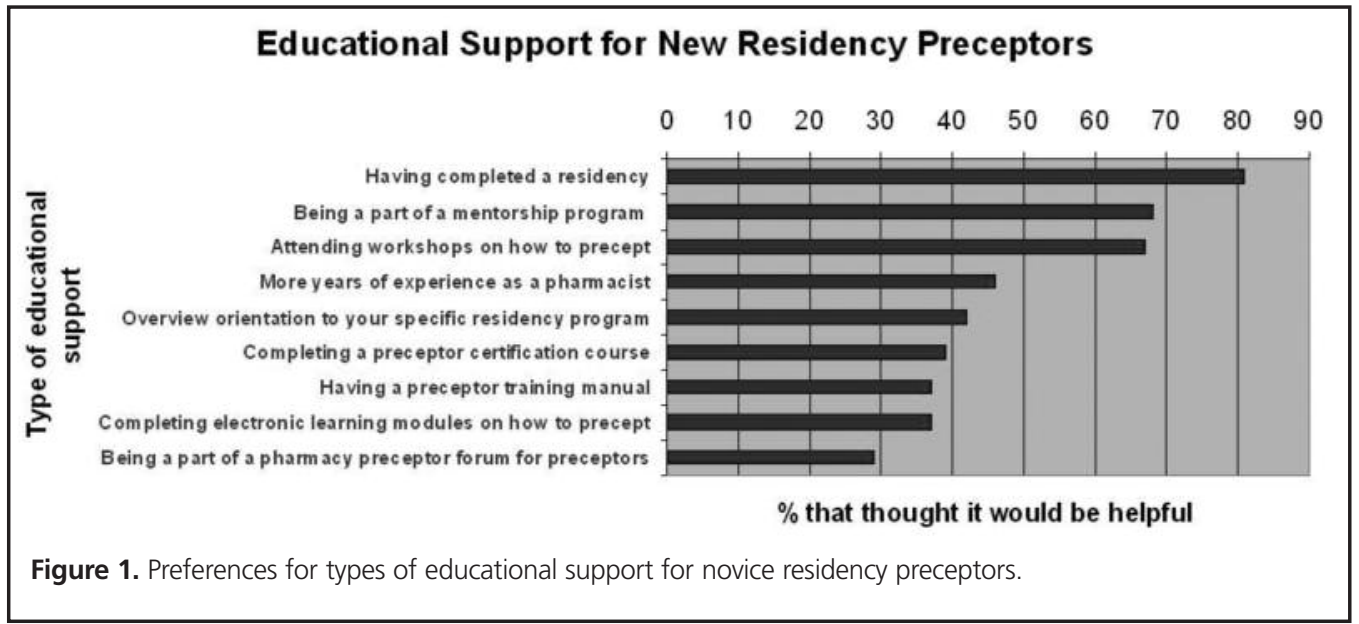

preceptors to their specific programs." Residency programs that allow for shadowing experiences for new preceptors were also appreciated.

Competence of residents: Responses indicated that a resident's abilities and competence often dictated whether the preceptor found that having a resident on service lightened or increased the workload (7 comments). One preceptor described this situation as follows: "When I have a high-functioning resident, I am MORE productive and able to manage patients, but when I have a less experienced resident, my ability to provide patient care is significantly compromised."

Several preceptors shared the notion that "having learners on clinical services clearly enhances patient care-they learn best by doing and by doing they help look after patients. Learners
Table 3. Beneficial Educational Support Topics as Rated by 116 Respondents

Topic*

Providing constructive feedback 115 (99)

Practical assessment strategies $\quad 114$ (98)

Small group teaching strategies 111 (96)

Effective communication skills 108 (93)

Setting goals and objectives 105 (91)

${ }^{\star}$ An additional 3 topics offered in the survey were rated as helpful by less than $90 \%$ of respondents.

are an asset, not a burden." Others wrote that "helping to model and shape the attitudes of professionals entering pharmacy is an incentive to precepting pharmacy residents." 


\section{Member Checking}

The final phase of the study, member checking, confirmed that the questions in the survey were clear and well worded. Participants in this phase felt that the survey had been successful in capturing the needs of hospital pharmacy residency preceptors. No concerns were brought to our attention by this process.

\section{DISCUSSION}

The goal of this study was to conduct a needs assessment focused on educational support for pharmacy residency preceptors. To the authors' knowledge, this was the first survey of preceptors from general hospital pharmacy residency programs across Canada for this purpose.

The response rate of $71 \%$ suggests high interest in preceptor development. Although preceptors from across Canada were invited to participate, we intentionally did not collect data on geographic location. It was thought that this information might reveal respondents' identities and remove anonymity; conversely, participation might have been hindered if participants thought they could be identified.

The first survey topic focused on the CHPRB standards. One-third of respondents indicated that they were not familiar with the standards before completing the survey, but after reading the standards, almost all respondents agreed or strongly agreed that they were confident of meeting the standards. This result indicates that the standards accurately reflect the current practices of hospital pharmacy residency preceptors.

The stated preference for interactive workshops over general workshops and participation in mentorship programs should be considered when preceptor development programs are created, as these preferences suggest that preceptors are dedicated to their responsibilities and would like to network with more experienced peers. Also, the preference for 1-day training sessions and electronic learning modules suggest that time and scheduling are consistent issues to be overcome.

For the questions with answers on a Likert-type scale, the neutral response option was selected only rarely. We believe this indicates that the questions were direct and that respondents could easily select their level of agreement. The only question for which the neutral response was the most common choice pertained to the confidence and competence that respondents felt when first starting to serve as a preceptor for pharmacy residents.

The next few paragraphs present our interpretation of the qualitative data from open-ended questions.

Teaching skills: Recurrent comments about interest in teaching and acquiring the necessary skills to teach effectively suggest that respondents to this survey were enthusiastic about their preceptorship responsibilities and appreciated opportunities to fulfill this role. The responses highlighted the differences in skill sets between teaching and working as a pharmacist.
These teaching and preceptorship skill sets, which include a range of skills in educating and instructing, communicating, completing evaluations, providing feedback, and being a role model, are rarely taught during pharmacy education. This discrepancy between preceptors' expressed interests and the training available to them emphasizes the need for relevant training and development in this area, in addition to mastery of clinical skills.

Time management and departmental support: Although formal preceptor training and development programs can improve individuals' time management skills, such training is not expected to affect departmental support. The latter must be addressed collaboratively by staff and administration for each particular program.

Individual program variability: Although CHPRB provides guidelines and accreditation standards to ensure consistency among programs, this aim is accomplished at the macro level, and some variability among programs is expected. Preceptors' needs, however, appear to be similar from one program to another, as demonstrated by the concordance of responses.

Competence of residents: Preceptors identified the competence of residents starting their residency as important. They expressed frustration or stated that they did not know how to help residents who were not meeting standards and expectations. The concept of producing students who function as helperlearners (i.e., students on experiential rotations who add to their own body of knowledge and skills by assisting their preceptor or mentor with workload) has been growing in pharmacy education. ${ }^{23}$ Specific to pharmacy practice, helperlearners assist in providing pharmaceutical care to patients and gain valuable experience, without hindering the preceptor's ability to provide care. If pharmacy residents could also be helper-learners, it would greatly reduce any burden a resident places on his or her preceptor, as functional ability upon arrival is a great asset to the workplace. Comments about residents' competence demonstrate that barriers to preceptorship are not always related to the preceptor but may also depend on the resident.

Overall, pharmacy preceptors appear to have a positive attitude toward working with residents. The barriers and challenges reported in this study most often correlated well with areas for which preceptors indicated they wanted additional educational support. This correlation, whereby respondents linked their self-identified learning needs with challenges that they were experiencing, shows that preceptors have good insight into their own learning needs and allows for confidence when developing preceptor training programs on the basis of these survey results. This clear interest in and appetite for preceptor development demonstrates not only that educational needs exist but also that preceptors are motivated to learn and would appreciate educational support. 
This study had a number of strengths, including the high response rate and the large sample size for this type of research..$^{20}$ The systematic study design, including the anonymous nature of data collection, reduced bias and helped to ensure validity and reliability. Internal validity was improved through multiple pilot tests before and member checking after the survey. A potential limitation was the possibility that preceptor selection at each site was not representative. It is therefore possible that the views of more or less experienced preceptors were not captured by the survey. Because of difficulties identifying pharmacists interested in but not currently serving as preceptors, we did not include such pharmacists in the study population, which may have limited generalization to this group. Exclusion of this subset prevented us from capturing accurate data on potential barriers to becoming a residency preceptor.

The results of this study provide direction for focused preceptor support activities and initiatives. Workshops, training sessions, and courses can be developed to help facilitate preceptor preparation, with the dual goals of better preparing new residency preceptors and supporting existing preceptors. The addition of this study to the existing literature is likely to benefit several parties. Residency program administrators will be able to implement initiatives to foster preceptor preparedness and ongoing development. Similarly, the CHPRB can gain a better understanding of preceptors' self-identified learning needs and can use the information to enhance development of both novice and experienced preceptors. Faculties of pharmacy can also provide focused continuing education for pharmacists who are interested in becoming preceptors for pharmacy residents.

\section{CONCLUSIONS}

This study identified several educational learning needs of hospital residency preceptors and demonstrated that preceptors would appreciate educational support. More specifically, preceptors felt confident that they met the CHPRB standards and ranked communication skills, giving effective feedback, and clinical knowledge as the most important elements of being an effective preceptor. Managing workload, evaluating residents, and dealing with difficult residents were common challenges. Participation in interactive workshops and mentorship programs with more experienced colleagues were preferred as educational methods when first becoming preceptors, with 1-day training sessions or electronic learning modules every other year preferred for ongoing educational support. The educational support topics identified by preceptors as being most beneficial were providing constructive feedback, practical assessment strategies, small group teaching strategies, effective communication skills, and setting goals and objectives. Use of these results by residency coordinators, program directors, the CHPRB, and faculties of pharmacy could benefit residency programs across Canada.
References

1. Burkiewicz JS, Zgarrick DP, Spunt AL. Opportunities for preceptor development in literature evaluation skills. Am J Pharm Educ 2006;70(5):123.

2. Billay DB, Yonge O. Contributing to the theory development of preceptorship. Nurse Educ Today 2004;24(7):566-574.

3. 2002 ASHP National Residency Preceptors Conference celebrates 40 years of programs, emphasizes caring. Am J Health Syst Pharm 2003;60(4): 386-390.

4. CSHP 2015 goals and objectives for pharmacy practice in hospitals. Ottawa (ON): Canadian Society of Health System Pharmacists; 2007.

5. Jennings HR, Empey PE, Smith KM. Survey of ASHP-accredited pharmacy residency programs. Am I Health Syst Pharm 2000;57(22):2080-2086.

6. Stamm M, Buddeberg-Fischer B. The impact of mentoring during postgraduate training on doctors' career success. Med Educ 2011; 45(5):488-496.

7. Kaviani N, Stillwell Y. An evaluative study of clinical preceptorship. Nurse Educ Today 2000;20(3):218-226.

8. Doerksen K. What are the professional development and mentorship needs of advanced practice nurses? J Prof Nurs 2010;26(3):141-151.

9. Morzinksi J. Mentors, colleagues, and successful health science faculty: lessons from the field. J Vet Med Educ 2005;32(1):5-11.

10. Moore M. Preceptorships: hidden benefits to the organization. J Nurses Staff Dev 2008;24(1):9-15.

11. Bergstresser PR. Academic mentoring. J Invest Dermatol 2011;131(2): 273-274.

12. Sonthisombat P. Pharmacy student and preceptor perceptions of preceptor teaching behaviours. Am J Pharm Educ 2008;72(5):110.

13. Canadian Hospital Pharmacy Residency Board accreditation standards January 2010. Ottawa (ON): Canadian Society of Hospital Pharmacists; 2009.

14. Preceptor development initiative. BC Academic Health Council; [cited 2010 Sep 13]. Available from: www.practiceeducation.ca

15. Preceptor education program for health professionals and students. London (ON): University of Western Ontario, Health Sciences; 2007 [cited 2010 Sep 13]. Available from: www.preceptor.ca

16. 1999 ASHP National Residency Preceptors Conference: mentoring for excellence. Am J Health Syst Pharm 1999;56(23):2454-2457.

17. Hoffman JM, Thomley S, Vermeulen L, Smith KM. Pharmacy residency training in academic medical centers. Am J Health Syst Pharm 2004 61(23):2528-2533.

18. Skrabal MZ, Kahaleh AA, Nemire RE, Boxer H, Broshes Z, Harris M, et al. Preceptors' perspectives on benefits of precepting student pharmacists to students, preceptors, and the profession. I Am Pharm Assoc 2006; 46(5):605-612.

19. Skrabal MZ, Jones RM, Nemire RE, Boyle CJ, Assemi M, Kahaleh AA, et al. National survey of volunteer pharmacy preceptors. Am J Pharm Educ 2008;72(5):112.

20. Moy D, Musing E. Canadian pharmacy practice residencies: a learning needs assessment. Can J Hosp Pharm 2003;56(5):259-266.

21. Marriott A, Taylor S, Simpson M, Bull R, Galbraith K, Howarth H, et al. Australian national strategy for pharmacy preceptor education and support. Aust J Rural Health 2005;13(2):83-90.

22. Russell CK, Gregory DM. Evaluation of qualitative research studies. Evid Based Nurs 2003;6(2):36-40.

23. Austin Z, Duncan-Hewitt W. Faculty, student and practitioner development within a community of practice. Am J Pharm Educ 2005;69(3): 381-389.

Christine Truong, BSCPhm, ACPR, RPh, is a Critical Care and Clinica Trials Pharmacist in the Department of Pharmacy, Mount Sinai Hospital, Toronto, Ontario.

Andrew Wyllie, BSCPhm, ACPR, PharmD, RPh, is a Drug Information Pharmacist in the Department of Pharmacy, Mount Sinai Hospital, Toronto, Ontario.

Toni Bailie, BSCPhm, ACPR, RPh, is the Residency Coordinator in the Department of Pharmacy, Mount Sinai Hospital, Toronto, Ontario.

Zubin Austin, BScPhm, MBA, MISc, PhD, RPh, is Associate Dean, Leslie Dan Faculty of Pharmacy, University of Toronto, and is also a Pharmacist in the Department of Pharmacy, Mount Sinai Hospital, Toronto, Ontario.

\section{Address correspondence to:}

Christine Truong

Department of Pharmacy

Mount Sinai Hospital

600 University Avenue, 18th floor

Toronto ON M5G $1 \times 5$

e-mail: ctruong@mtsinai.on.ca 